\title{
Analysing the effect of cutting fluids on the mechanical properties of mild steel in a turning operation
}

\author{
${ }^{1}$ Patrick Adebisi Olusegun Adegbuyi; ${ }^{2}$ Ganiyu Lawal; ${ }^{3}$ Oluwatoyin Oluseye; \\ ${ }^{4}$ Ganiyu Odunaiya \\ ${ }^{(1,3,4)}$ Department of Mechanical Engineering, Lagos State University, P M B 1087 \\ Apapa-Lagos, Nigeria \\ (2) Department of Metallurgical and Materials Engineering, University of Lagos \\ Akoka, Yaba, Lagos
}

\begin{abstract}
Cutting fluids are used in machining for a variety of reasons such as improving tool life, reducing work-piece thermal deformation, improving surface finish. Mota and Machado (1995) concluded that reducing cutting tool cost and increased production can be achieved through the use of appropriate cutting fluids. In this work soluble oil, water and palm kernel oil were used as coolants in turning operations. Tungsten carbide and HSS cutting tools were employed as cutter with cutting speed of 355rpm. Turning was done under dry condition and also using 3 coolants. Temperature and Hardness values after each cut were recorded. The microstructure of all the specimen was also done and recorded. It was revealed that variation in the Hardness value of the samples with progress in machining time is more with the use of carbide tool compared to the HSS cutter.Samples cooled with water exhibited the highest hardness value. Palm kernel oil performed very well the specific functions of soluble oil as cutting fluid which includes good chip formation, reduction of heat generated and realization of a good surface finish The analysis are shown in tabular and graphical form in chapters 3 and 4
\end{abstract}

Keywords: Effect, Cutting fluids, Mechanical properties, Mild steel

\section{INTRODUCTION}

Cutting fluids are used in metal machining for a variety of reasons such as improving tool life, reducing work piece thermal deformation, improving surface finish and flushing away chips from the cutting zone. In the 19th-century machining practice, it was not uncommon to use plain water. This was a simple practice used to keep the cutter tool cool, regardless of whether or not it provided any lubrication at the cutting edge-chip interface. When one considers that high-speed steel (HSS) had not been developed then, the need to cool the tool becomes all the more apparent. (HSS retains its hardness at high temperatures while other carbon tool steels do not). An improvement was soda water, which better inhibited the rusting of machine slides. These options are generally not used today because better options are available. Lard was very popular in the past. It is used less often today, because of the wide variety of other options, but it is still a fine option.

Old machine shop training textbooks speak of using red lead and white lead, often mixed into lard or lard oil. This practice has become obsolete because lead is hazardous to health, and excellent non-leadcontaining options are now available.

From the mid-20th century to the 1990s, 1, 1, 1trichloroethane was used as an additive to make some cutting fluids more effective. In shop-floor slang, it was referred to as "one-one-one". It has been phased out because of its ozone-depleting and CNS-depressing properties.

Metal cutting operations involve generation of heat due to friction between the tool and the workpiece and due to the energy lost during the deformation of the material. The surrounding air independently is a rather poor coolant for the cutting tool, because the rate of heat transfer is low. Ambient-air cooling is adequate for light cuts with periods of rest in between, such as are typical in maintenance, repair and operations (MRO) work or hobbyist contexts. However, for heavy cuts and constant use, such as in production work, more heat is produced per time period than ambient-air cooling can remove. It is not 
acceptable to introduce long idle periods into the cycle time to allow the air-cooling of the tool to "catch up" when the heat-removal can instead be accomplished with a flood of liquid, which can "keep up" with the heat generation.

In the context of metalworking, a cutting tool (or cutter) is any tool that is used to remove metal from the workpiece by means of shear deformation. Typical examples are tool bits, drill bits, and milling cutters. Technically, grinding wheels are a subset of cutting tools, as grinding is a true metal cutting process. Each grain of abrasive functions as a microscopic single-point cutting edge (although of high negative rake angle), and shears a tiny chip that is analogous to what would conventionally be called a "cut" chip (turning, milling, drilling, tapping, etc.). However, among people who work in the machining fields, the term "cutting" is most often understood to refer to the macroscopic cutting operations, and grinding is mentally categorized as a "separate" process. This is why the terms "cutting" and "grinding", or "machining" and "grinding", are often used in contra-distinction in shop-floor practice, even though technically grinding is a subset of cutting. Consequently, the term "cutting tool" is often used to refer to all cutters used in "regular" (non-grinding) machining, and thus to exclude grinding wheels.

Cutting tools must be made of a material harder than the material which is to be cut, and the tool must be able to withstand the heat generated in the metalcutting process. Also, the tool must have a specific geometry, with clearance angles designed so that the cutting edge can contact the workpiece without the rest of the tool dragging on the workpiece surface. The angle of the cutting face is also important, as is the margin size. In order to have a long working life, all of the above must be optimized.General speaking, metal working mass production techniques can be traced back to the $16^{\text {th }}$ century, but it was really not until the late $18^{\text {th }}$ century that engineers in the industrialised countries paid close attention to increasing production, due to the vast rise in their population a significant industrial growth. In Europe at that time, two countries where important areas of applied machining and fluid research were pursued was: In France, where the machining of metals was being investigated and developed into sciencespecifically in terms of the effects of tool feeding and lubrication and its effect on surface finish.
Also in the mid $19^{\text {th }}$ century in England, where the effects of water as a coolant to enhance tool performance was also studied [4]Thus, as this research activities progressed, complimentary advances were taken place into the study of tool materials, their heat treatment and in particular, tool hardening techniques. As has happened on many occasions in the past, considerable advances took place as a result of the enormous demands for permanent manufacturers and their production needs during times of war, significantly adding advancements and refinements to the: machine tools; tooling; as well as for lubricants (cutting fluids)[9]

An essential requirement of good cutting fluids is that they provide proper lubrication, cooling and chip removal[7] Lubrication decreases the friction between the workpiece and the cutting tool, reducing the generation of heat and cutting forces, while cooling ensures the workpiece is kept at low temperatures to prevent thermal damages such as cracks. The third task of cutting fluids is to remove the chips generated in the cutting zone, preventing them from entering into contact with the workpiece, which might impair the final smoothness.

According to [2] the effective application of cutting fluids can also increase the cutting tools life, improve roughness and dimensional precision and reduce the consumption of energy.

Therefore,[10] conclusions about reducing cutting tools cost and increased production being achieved through the use of appropriate cutting fluids are highly justified. The cutting fluid should meet the specific requirements of the turning process. In addition to the cooling effects, cutting fluids can lubricate the workpiece, acting decisively to maintain the good quality of the final piece. This fact makes cutting fluids one of the most important parameters in a turning operation process. With regards to the characteristics of cutting fluids, pure oil is believed to have a high lubricating capacity while emulsion has a high cooling capacity.

According to [5] a jet of fluid striking squarely upon the cutting region can decrease the region's temperature considerably; however high fluid jet velocities are required for the fluid to effectively penetrate the cutting region.

It was also found that the angle of incidence of the jet in the cutting region does not substantially lower the temperature of the workpiece [5] however, the tool's peripheral velocity in relation to the fluid jet is very important in the cooling process of the workpiece. 
Researches have shown the different kinds of fluids that have been tried for substituting (emulsifiable oils) , soluble oils which were obtained from animal fat, fish, petroleum, coconut, groundnut etc. had actually played the role of cutting fluids but a lot of disadvantages like strong smoking, unpleasant odours, high cost were discovered [1] Finally, the objective of this work is to determine the surface roughness and mechanical properties of mild steel using different cutting tools and cutting fluids. The results would be useful and applicable in precision cutting.

\section{METHODOLOGY/EXPERIMENTAL}

The research work was carried out at the metallurgy workshop, Lagos State University, Faculty of Engineering, Epe Campus. Two of the cutting fluids (water and soluble oil) with the cutting tools (Tungsten carbide and HSS) were both obtained from the workshop. The other cutting fluid (palm kernel oil) and the workpiece (mild steel) were sourced for locally.

The experiment was carried out on a center lathe machine. The work piece was inserted into the 3-jaw chuck and the jaws were tightened down until the jaw start to grip the workpiece. The Tungsten Carbide cutting tool was tightly clamped in the tool holder and the angle of the tool holder was adjusted so that the Tungsten Carbide tool was approximately perpendicular to the side of the workpiece.

The cutting speed was set to $355 \mathrm{rpm}$ and the laboratory attendant assisted in turning the carriage hand wheel counter clockwise to slowly move the carriage towards the headstock while I continued to apply the cutting fluid with a help of a hand pump. The process was repeated continuously until a certain diameter for the workpiece was reached. The diameter of the workpiece was also determined using a vernier caliper. These steps were repeated for subsequent cutting fluids while a set was cut dry and after the results of the four samples have been derived using the Tungsten Carbide cutting tool, the overall process was repeated using the HSS cutting tool. The cutting temperatures were also taken immediately after each cutting and the values are shown in the table in section 3.1.

\section{HARDNESS TEST}

The hardness test was carried out using materials testing apparatus WP300 (G.U.N.T Hamburg). The hardness test carried out was Brinell hardness.
Four specimens were prepared each for the Carbide and HSS cutting tools. A hardened steel ball was pressed into the prepared surface of each of the specimen for a given time (20 secs) under a specified load $(9.8 \mathrm{KN})$. The diameter of the impressed that was produced was measured and the hardness volume was calculated on the basis of load supported per unit area of the indentation. The Brinell hardness value for each experiment was derived from the mathematical expression stated below:

$$
\begin{aligned}
& H B=\frac{0.102 \times 2 \times F}{\text { surface area of }} \\
& =\frac{0.102 \times 2 F}{\pi D\left[D-\left(\sqrt{D^{2}-d^{2}}\right)\right]}
\end{aligned}
$$

Where:

$$
\begin{aligned}
& F=9800 \mathrm{~N} \text { (load factor) } \\
& D=15 \mathrm{~mm} \text { (diameter of steel ball) } \\
& d=\text { diameter of indentation }(\mathrm{mm})
\end{aligned}
$$

\section{METALLOGRAPHY OF MILD STEEL}

The most important phase of this experiment is the microscopic examination of mild steel that has been subjected to a turning operation using Carbide and HSS cutting tools as well as different cutting fluids. The micrograph utilizes a high magnification microscope to give more detailed information. It defines clearly the structural phases and nonequilibrium conditions all of which are the result of the previous history of the samples and its composition which makes it possible to predict with considerable accuracy the expected behaviour of the mild steel for a specific purpose.

Techniques of metallographic are important in:

- Identifying the past history of the metal or alloy

- Predicting its physical and mechanical properties

- Analysis of a compound failure

- Evaluation of material for design and application 


\section{PROCEDURES}

i. The surface of each specimen was mounted on a bench vice and filed.

ii. The surface of each specimen was further grinded on a grinding/polishing machine to give it a smoother finish using silicon carbide powder

iii. After the surface has been finely grinded, it was washed with water to remove grounded particles.

iv. The surfaces were polished using mercury paste as abrasive on the polishing machine.

ANALYSIS OF RESULTSIDISCUSSION AND CONCLUSION v. Each specimen was washed in running water thoroughly after the surface had achieved a mirror like shining face after successive polishing.

vi. Each specimen was then etched by immersing it in potassium nitrate (niter) using a metal tong for about 30 seconds and later immersed in alcohol (ethanol) for 20 seconds and later rinsed in water after which it was allowed to dry with the aid of a blowing fan.

vii. The specimens were then taken to the dark room to observe their microstructures with the aid of a high magnification microscope

THE VARIATION OF TEMPERATURE OF THE WORKPIECE USING DIFFERENT CUTTING FLUIDS ON A LATHE MACHINE

\begin{tabular}{|l|c|c|c|c|}
\hline SPECIMEN & $\begin{array}{c}\text { CUTTING } \\
\text { TOOL }\end{array}$ & $\begin{array}{c}\text { CUTTING } \\
\text { FLUID }\end{array}$ & $\begin{array}{c}\text { SPEED } \\
\text { (RPM) }\end{array}$ & $\begin{array}{c}\text { TEMPERATURE } \\
\text { AFTER TURNING } \\
\left({ }^{\circ} \mathrm{C}\right)\end{array}$ \\
\hline $\mathbf{1}$ & HSS & WATER & 355 & 33 \\
\hline $\mathbf{2}$ & HSS & DRY CUTTING & 355 & 37 \\
\hline $\mathbf{3}$ & HSS & PALM KERNEL OIL & 355 & 36 \\
\hline $\mathbf{4}$ & HSS & SOLUBLE OIL & 355 & 34 \\
\hline $\mathbf{5}$ & CARBIDE & WATER & 355 & 34 \\
\hline $\mathbf{6}$ & CARBIDE & DRY CUTTING & 355 & 39 \\
\hline $\mathbf{7}$ & CARBIDE & PALM KERNEL OIL & 355 & 38 \\
\hline $\mathbf{8}$ & CARBIDE & SOLUBLE OIL & 355 & 32.5 \\
\hline
\end{tabular}

Ambient temperature $=30^{\circ} \mathrm{C}$ 


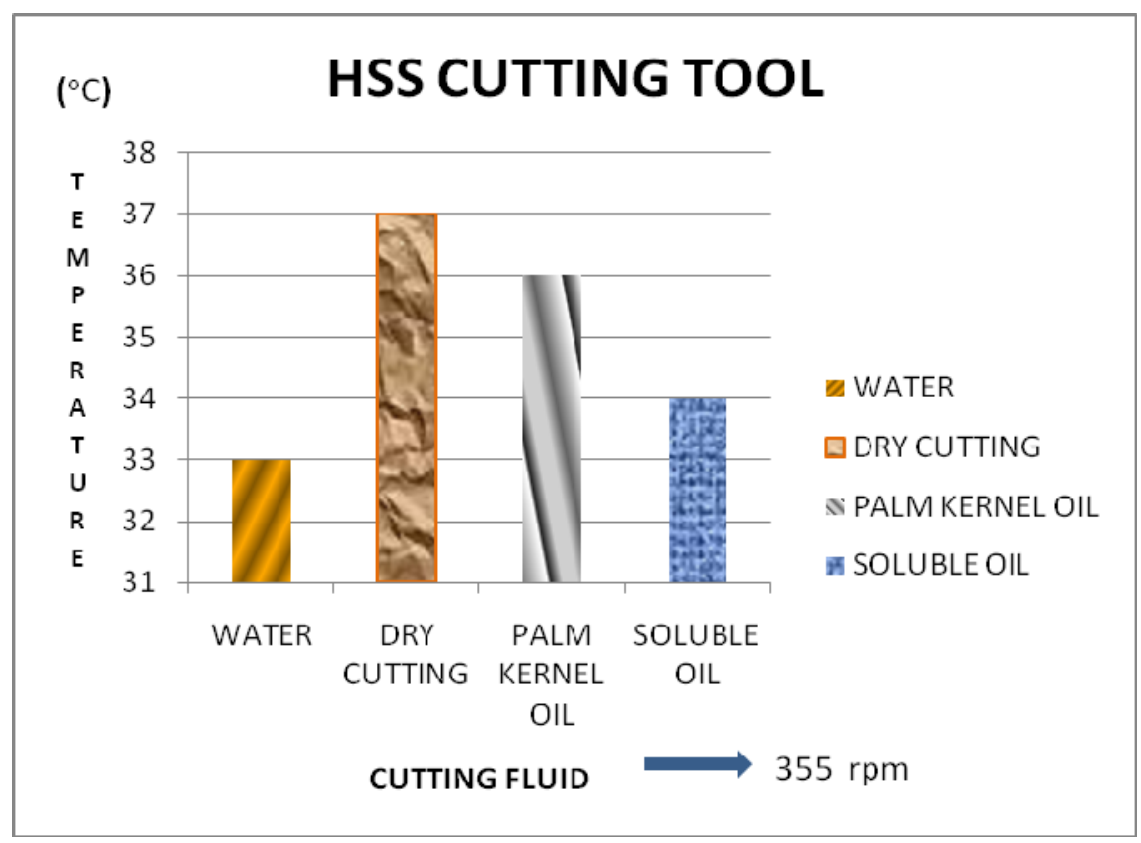

Fig 3.2: Graph of temperature variation during cutting and cooling for HSS cutting tool

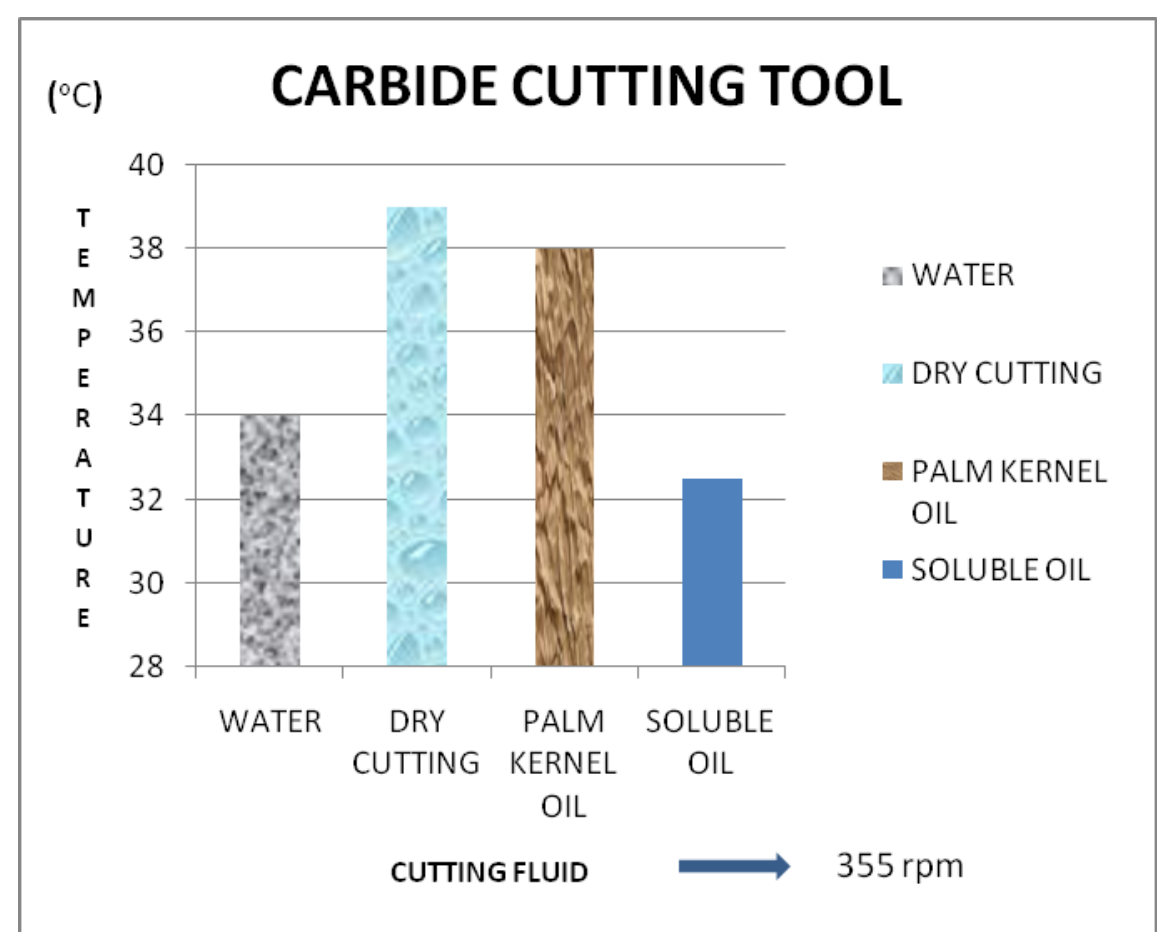

Fig 3.3: Graph of temperature variation during cutting and cooling for carbide cutting tool 
Am. J. Sci. Ind. Res., 2011, 2(1): 1-10

THE HARDNESS OF MILD STEEL USING DIFFERENT CUTTING FLUIDS IN A TURNING OPERATION BASED ON THE BRINELL HARDNESS TEST

\begin{tabular}{|l|l|l|l|l|}
\hline SPECIMEN & $\begin{array}{l}\text { CUTTING } \\
\text { TOOL }\end{array}$ & $\begin{array}{l}\text { CUTTING } \\
\text { FLUID }\end{array}$ & $\begin{array}{l}\text { DIAMETER } \\
\text { INDENTATION } \\
(\mathbf{d} / \mathbf{m m})\end{array}$ & $\begin{array}{l}\text { OF } \\
\text { BRINELL } \\
\text { HARDNESS } \\
\left(\mathbf{N} / \mathbf{m}^{2}\right)\end{array}$ \\
\hline 1 & HSS & WATER & 2.45 & 211 \\
\hline 2 & HSS & DRY CUTTING & 2.50 & 202 \\
\hline 3 & HSS & PALM KERNEL OIL & 2.60 & 187 \\
\hline 4 & & & \\
\hline 5 & HSS & SOLUBLE OIL & 2.60 & 187 \\
\hline 6 & CARBIDE & WATER & 2.55 & 194 \\
\hline 7 & CARBIDE & DRY CUTTING & 2.60 & 187 \\
\hline 8 & CARBIDE & PALM KERNEL OIL & 2.70 & 173 \\
\hline
\end{tabular}

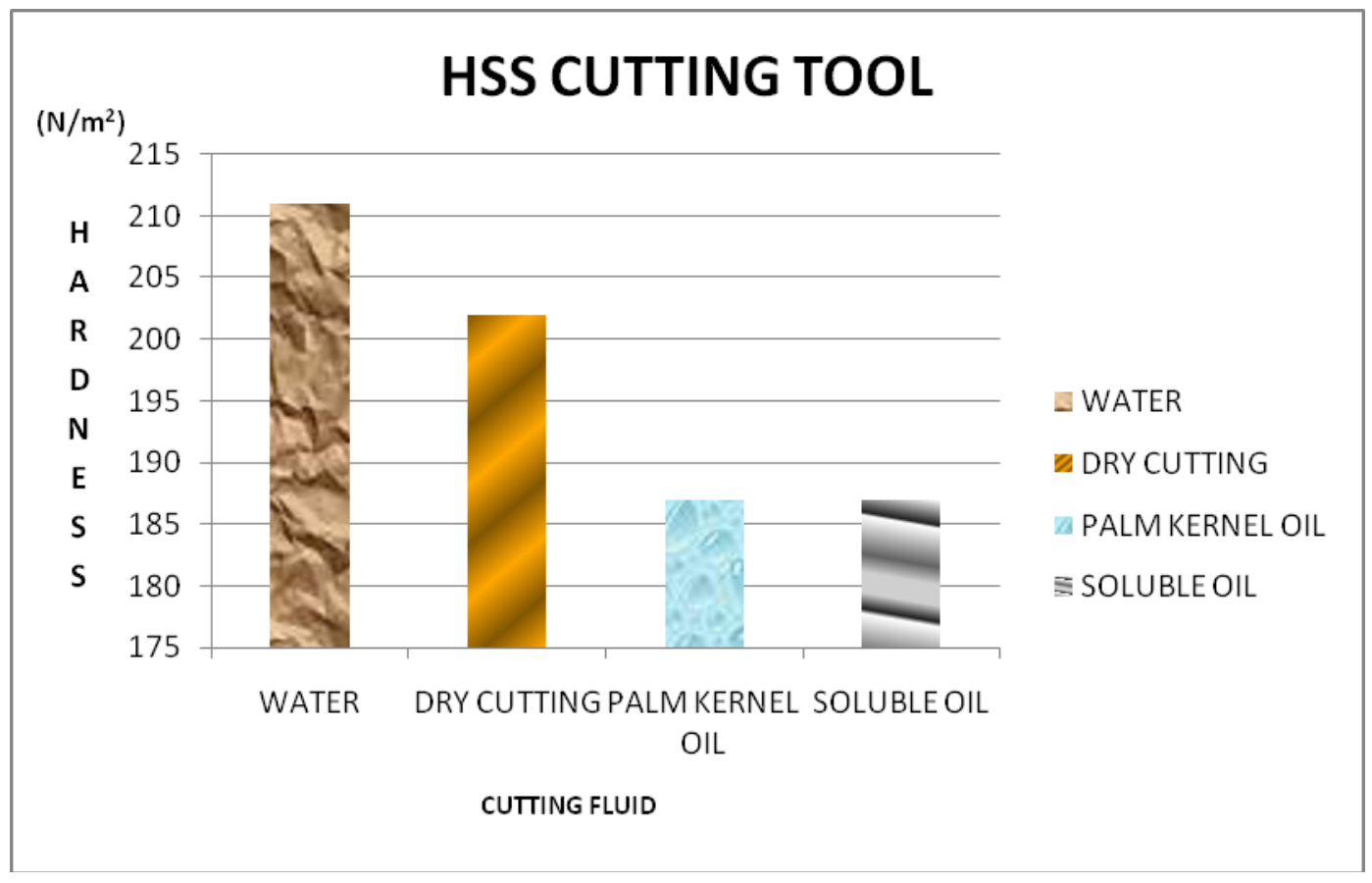

Fig 3.4.1: Hardness values for HSS cutting tool in different medium of cooling 
Am. J. Sci. Ind. Res., 2011, 2(1): 1-10

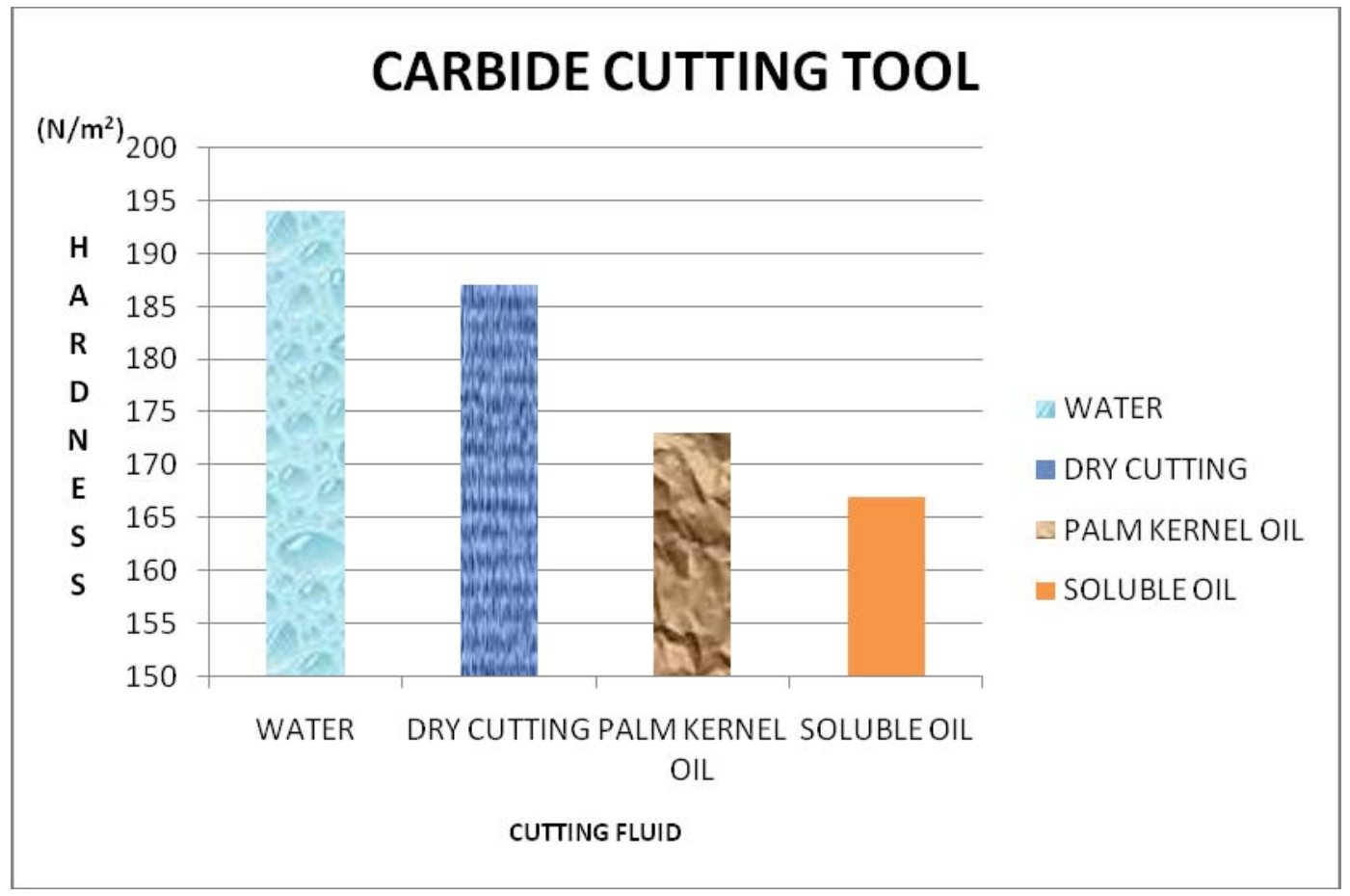

Fig 3.4.2: Hardness values for carbide cutting tool in different medium of cooling

\subsection{MICROGRAPHS OF EACH SPECIMEN SHOWING MICROSTRUCTURE}

\section{Specimen 1}

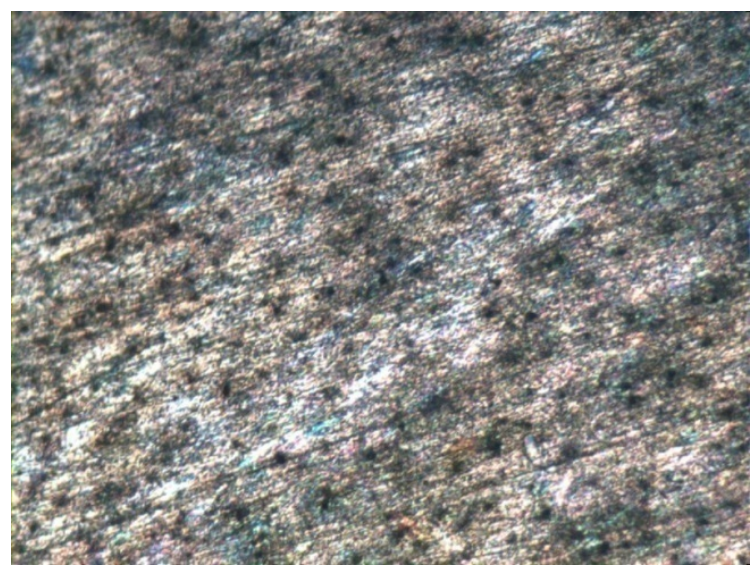

Fig 4.1 Specimen using dry cutting and carbide cutting tool

\section{Specimen 2}

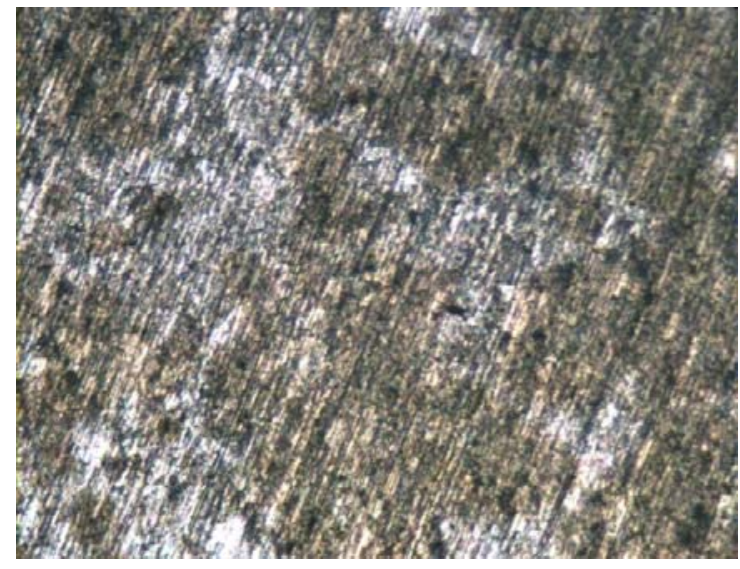

Fig 4.2 Specimen using water as cutting fluid and carbide cutting tool 
Am. J. Sci. Ind. Res., 2011, 2(1): 1-10

\section{Specimen 3}

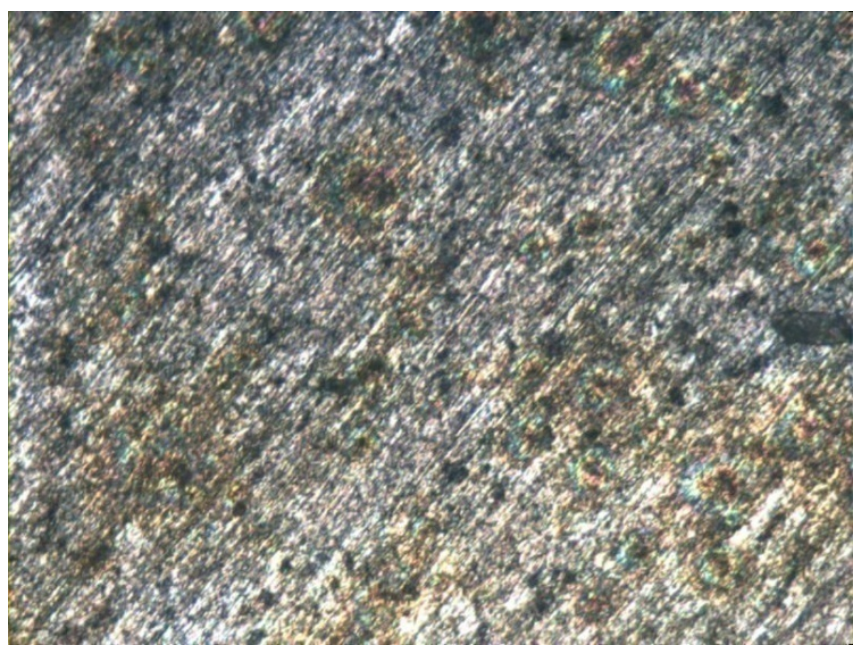

Fig 4.3 Specimen using palm kernel oil as cutting fluid and carbide cutting tool

\section{Specimen 4}

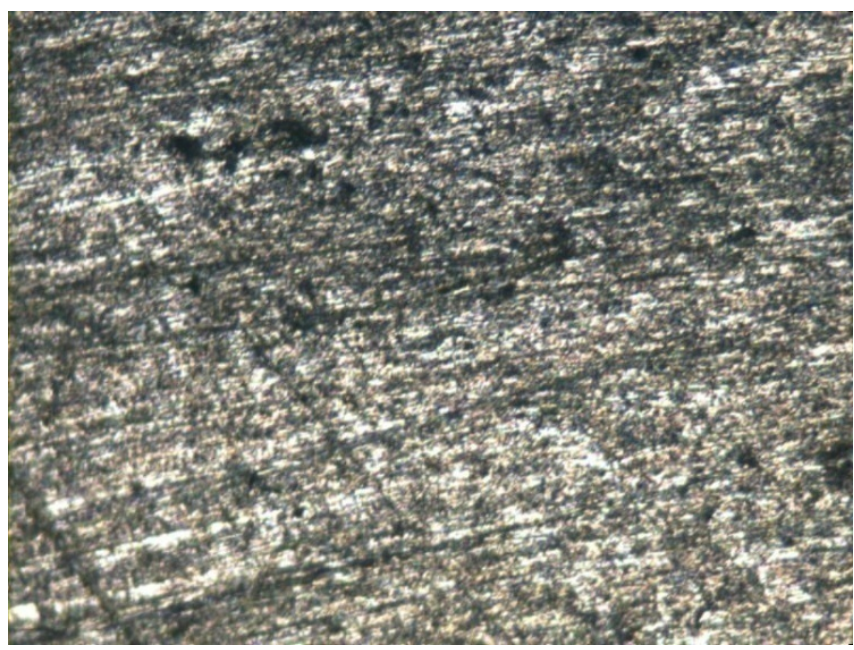

Fig 4.4 Specimen using soluble oil as cutting fluid and carbide cutting tool

\section{Specimen 5}

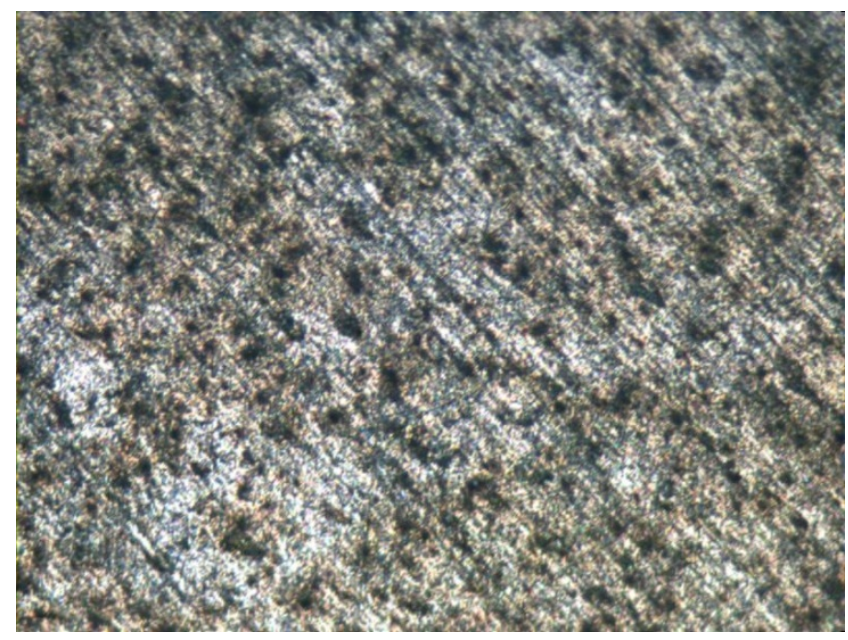

Fig 4.5 Specimen using dry cutting and HSS cutting tool

\section{Specimen 6}

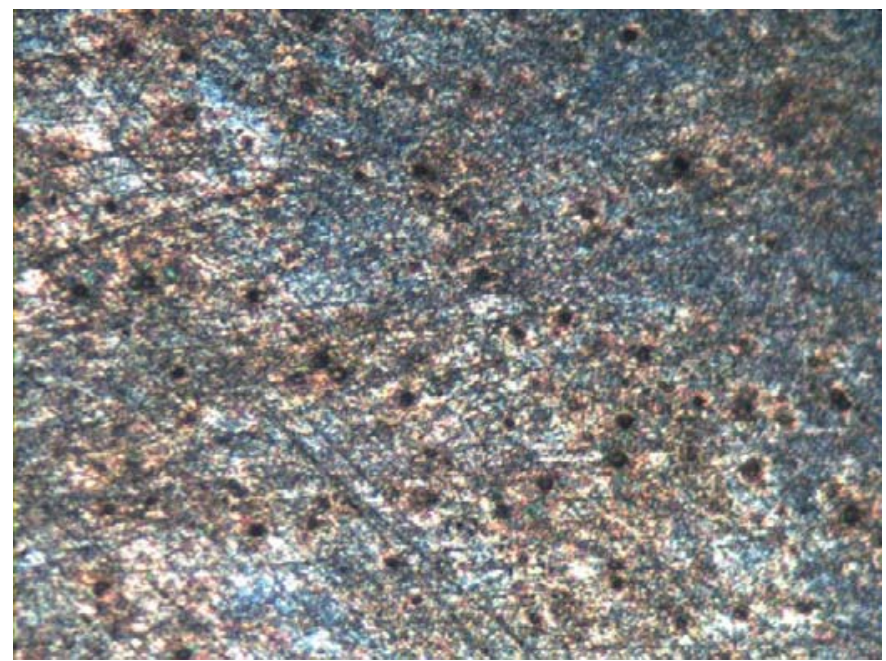

Fig 4.6 Specimen using water as cutting fluid and HSS cutting tool 


\section{Specimen 7}

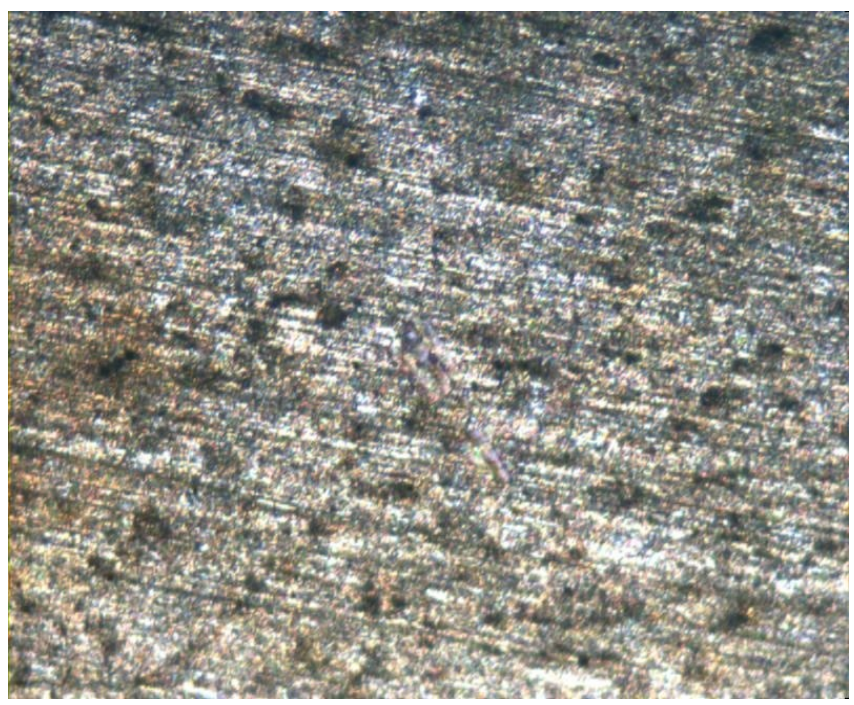

Fig 4.7 Specimen using palm kernel oil as cutting fluid and HSS cutting tool

\section{Specimen 8}

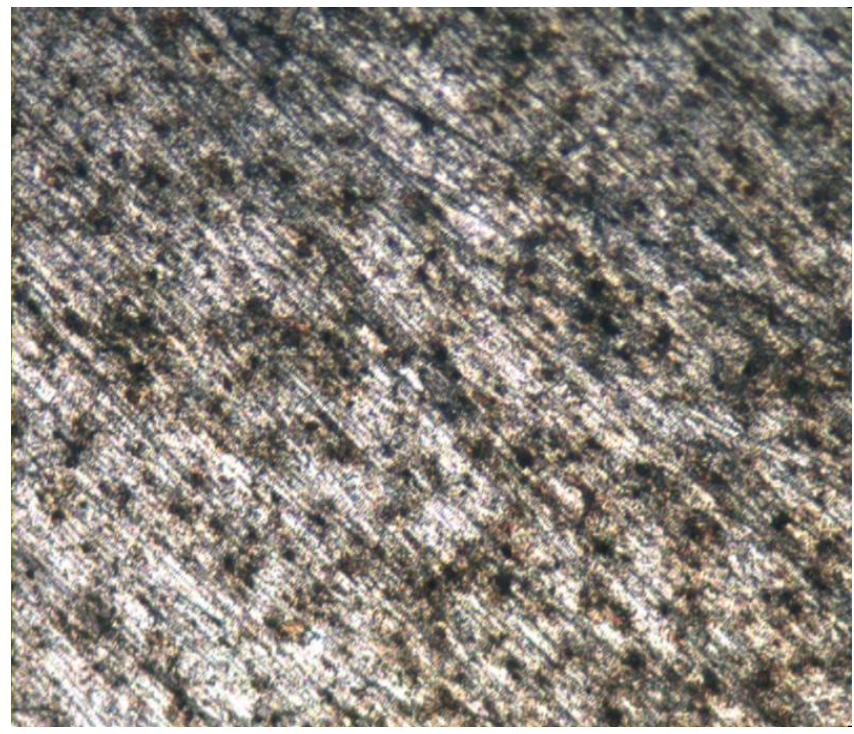

Fig 4.8 Specimen using soluble oil as cutting fluid and HSS cutting tool

\section{DISCUSSION}

As cutting fluid is applied during machining operations, it removes heat by carrying it away from the cutting tool/workpiece interface. This cooling effect prevents tools from exceeding their critical temperature range beyond which the tool softens and wears rapidly. Fluids also lubricate the cutting tool/workpiece interface, minimizing the amount of heat generated by friction. A fluid's cooling and lubrication properties are critical in decreasing tool wear and extending tool life. Cooling and lubrication are also important in achieving the desired size, finish and shape of the workpiece.

No one particular fluid has cooling and lubrication properties suitable for every metalworking application. Straight oils provide the best lubrication but poor cooling capacities. Water, on the other hand, is an effective cooling agent, removing heat 2.5 times more rapidly than oil. Alone, water is a very poor lubricant and causes rusting. Soluble oils or chemicals that improve lubrication prevent corrosion and provide other essential qualities must be added in order to transform water into a good metalworking fluid. The study of the hardness test together with the micrographs reveals the following:

- Variation in the hardness of the samples with progress in machining time is more in case of samples machined using Carbide tool compared to HSS tool, the reason being higher tool tip temperatures generated in carbide tool. However in both cases, samples machined using different cutting fluids vary significantly in terms of hardness.

- It was be deduced that water when used as a cutting fluid gives the highest hardness of the workpiece material.

- The hardness values obtained shows that palm kernel oil and soluble oil gave the lowest values but observed that palm kernel oil performed very well the specific functions of soluble oil as cutting fluid which includes good chip formation, reducing heat generated by cooling the workpiece and realisation of the desired surface finish.

- From the physical examination of the samples, micrographs and based on past research work and established literature indicated that the specimen with the highest hardness value has the finest grain structure, it can be deduced that water as a cutting fluid produces the finest grain structure.

\section{REFERENCES}

1. Adegbuyi P.A.O. (2003) "Indigenous Oil as cutting fluid" Engineering and Technology Research journal, volume 1 no 1,page 15-25, Faculty of Engineering, Technology and 
Environmental Sciences, Lagos State University, Lagos, Nigeria

2. El Baradie M. A., (1996) "Cutting fluids part 1: Journal on characterisation of material processing technology" page 786-787

3. Radoslav Raki A., Zlata Raki B. (2002) "The influence of the metal working fluids on machine tool failures" volume 252 no 5-6: page 438-444

4. Srikant R.R. (2001): Department of industrial production, college of engineering, Gitam, Visakhapatnan, India.

5. Greeley M. H., Devor R.E, Kapoor S. G., Rajagopalan N (2004).. "The influence of fluid management policy and operational changes on metal working fluid functionality. Journal on manufacturing science engineering. volume 126.

6. Bashir Andrei. N. (2004) Proceedings on the institution of mechanical engineers, part $\mathrm{J}$ : Journal of engineering tribology.

7. OSHA Metal working fluids: Safety and health best practices manual, Salt lake City, US dept. of Labour, OSHA. (1999)
8. Aronson R. B. (1994), "Machine Tool 101: part 6, machine servers manufacturing engineering": page 47-52

9. Avner, S.H. (1998), "Introduction to physical metallurgy", second edition, Tata Mc GrawHill publishing company Ltd, New Delhi, page 297-302

10. Motta, M. F. And Machado, A. R. (1995) "Cutting fluids; Types, functions, selection, application methods and maintenance", Machines and Metals magazine, Brazil page 45-56

11. Radoslav Raki A., Zlata Raki B. (2002) "Tribolical aspects of the choice of metal working fluid in cutting processes", Journal of material processing technology, volume 124 , no $1-2$, page $25-31$

12. Journal of the Brazilian Society of Mechanical Sciences and Engineering, volume 30, no 2. (April - June 2008)

13. Tool Engineer Handbook : (1959) "Society of Manufacturing Engineering (SME)" second edition, Mc Graw-Hill Intl. Company, London 